\title{
How to Motivate Adults to Check for Alzheimer's Disease (AD) Using Three Types of Triggers
}

\author{
Sarah Alismail \\ Claremont Graduate University \\ sarah.alismail@cgu.edu
}

\author{
Hind Bitar \\ Claremont Graduate University \\ hind.bitar@cgu.edu
}

\author{
Swati Ramani \\ Claremont Graduate University \\ swarti.ramani@cgu.edu
}

\begin{abstract}
In the United States, about 1/3 of seniors die with Alzheimer's Disease (AD) or a related dementia. Age, family history, education, and lifestyle are some of the most important factors leading to $A D$ among adults. This research paper investigates how to motivate adults who are 50 years or older to visit a/their primary physician regularly in order to discover $A D$ in the early stage by the influence of three triggers. Fogg's Behavioral Model (FBM) was used as the basis for this study. This research involved conducting semi-structured interviews in three case studies using three triggers: oral documentation, video, and a smartphone app. The findings showed that the smartphone app and the oral documentation triggers had a positive impact in motivating people to have the intention to carry out the target behavior. However, the video trigger had low impact in terms of motivating people.
\end{abstract}

\section{Introduction}

Alzheimer's disease (AD) is a "type of dementia that causes problems with memory, thinking, and behavior" [1]. According to an Alzheimer's Association report, there are 5.2 million people aged 65 years and older in the United States who have AD, and this number has been increasing (2014). Moreover, about $1 / 3$ of seniors die with $\mathrm{AD}$ or a related dementia in the United States [2], and caregivers and families spend around 17.7 billion hours taking care of AD patients. In 2014, the public health report stated that $\$ 214$ billion is the total cost for long-term care and hospital services for people aged 65 years and older who have dementia. The symptoms in $\mathrm{AD}$ patients appear after 20 years from the disease exposure, and during that time, $\mathrm{AD}$ patients can do their daily jobs and activities without any problems.

Since the substantial medical costs of treating AD affect not only the patients, but their families and society as a whole, early diagnosis of the disease could reduce many of the negative effects. The problem is that early diagnosis of $\mathrm{AD}$ is difficult [3]. Therefore, the question that this research addressed was this: what is the influence of using three triggers in motivating people who are 50 years or older to visit primary physicians regularly to discover $A D$ in an early stage? The reason for choosing the age group of 50 and above was because, according to the Alzheimer's Association (2014), usually a specialist diagnoses people with $\mathrm{AD}$ at the age of 65 , since the symptoms start to appear after 20 years of having the disease. Thus, the age of participants had to fall in a range from 45 to 65 to assist in early diagnosis. Initially, we chose three people randomly aged 45 to 49 to participate in the study. However, we perceived that those people did not consider themselves to have AD. Hence, we increased the age of the participants to 50 years old and above. To answer the research question, the researchers conducted three case studies: each had five participants 50 years old and above. The data collection technique used was a semi-structured interview. Coding was used as a data analytical approach.

The main goal of the research was to understand the impact of using three triggers in motivating people to visit their primary physicians to check for $\mathrm{AD}$ disease in its early stage. The research is based on the Fogg Behavior Model (FBM), where behavior is a result from three main elements: motivation, ability, and trigger [4].

\section{Literature Review}

There are many studies about the relationship between $\mathrm{AD}$ and others factors such as education level, lifestyle, and environment. There are some factors that cannot be changed such as age and family history. However, there are other factors that can be influenced, like educational level and lifestyle.

Age-related changes are one of the most common causes of Alzheimer's disease [5]. According to research on normal brain aging, age-related changes 
in the brain harm neurons and contribute to Alzheimer's damage. Age-related changes like atrophy (shrinking) of certain parts of the brain, inflammation, production of unstable molecules called free radicals, and mitochondrial dysfunction (a breakdown of energy production within a cell) are most common for this disease [5]. Alzheimer's is caused by brain cell death. It is a neurodegenerative disease. There is a progressive brain cell death that happens over the course of time. The total brain size shrinks, and the tissues have fewer nerve cells and connections [6].

Family history is another factor that may play a role in the development of AD. First-degree relatives of an individual diagnosed with $\mathrm{AD}$ have about $25 \%$ risk of developing the disease. The risk of having the disease increases to other first-degree relatives in cases where there are multiple affected family members [7, 2].

According to Jankowsky et al. (2005), there is a strong relationship between the disease and education level. The more education a person has, the less chance he/she has to develop AD. Interacting with people and exercising could also reduce the risk of developing dementia, which is an important sign of AD. In general, challenging mental activity will assist in controlling and reducing the chance of developing the disease. In addition, it has been proven by imaging techniques that performing cognitive activities and functions engage new areas in an elderly person's brain, thus improving the ability to recall past information [8]. Additionally, considering lifestyle and health, Merchant et al (1999) examined the effect of cigarette smoking on AD risk and found that smoking does, in fact, raise the risk of developing AD [9].

\section{Theoretical Foundation}

This research is primarily founded on the FBM, which is simply expressed by the $b=$ mat equation. The $b$ stands for behavior, which is the outcome of motivation, ability, and trigger, and all must occur at the same moment. If one of these elements does not exist, the behavior change does not occur [4].

The ability element can be increased through either training individuals or simplifying the target behavior. The trigger is a visible object that is an essential element. Without it, the object behavior cannot occur, so it assists in behavior change [10]. The following demonstrate the three types of triggers [4]:

- Facilitator: high motivation with low ability

- Signal: high ability with high motivation

- Spark: high ability with low motivation
The last element is the motivation, which could include Sensation (pain or pleasure), Anticipation (fear or hope), or Belonging (rejection or acceptance) [4]. For example, in this study, the participant could have experienced pain due to losing a first degree relative with $\mathrm{AD}$, or developed a fear of having the disease or losing somebody else. Our objective and reason for selecting this model was to understand the impact of three types of triggers on behavior change, with the behavior change being checking for $\mathrm{AD}$ in an early stage.

\section{Methodology}

This research looked at three case studies based on three different triggers. The first trigger was simple oral documentation that explained AD and all the side effects (Information retrieved from Alzheimer's Association, 2016). The second trigger was a real life video that showed the middle stage of an AD patient [11]. The last trigger was a smartphone application that explained the disease in advance with some interaction features (see Appendix A). The philosophical approach was positivist qualitative study, since the researchers tried to test and understand the best way to motivate people to take the action or make a decision to visit their primary physician and check for AD. Using the case study approach as a research method was beneficial, since the researchers were focused on investigating and understanding how to motivate people.

The researchers began with two hypotheses. The first hypothesis applied to both oral documentation and video case studies: more awareness of the disease could motivate people to visit their primary physician and check for the disease. The second hypothesis applied to the smartphone app case study: more awareness of the disease and having an interactive technology tool could contribute to a change in people's behavior and encourage them to ask for initial diagnoses through the app and visit their primary physicians. The data collection technique that was used was a semi-structured interview. The researchers conducted a pilot test through interviewing three participants, randomly selected from the public. Then, adjustments were made to the questions to get more precise answers that would help in answering the research question. More questions were developed based on the conversation between the interviewer and the interviewee. The sample consisted of three case studies, five participants in each, selected randomly from two 
cities: Loma Linda and Claremont ${ }^{1}$.

The interviews ranged from 15 to 30 minutes. The profile of the sample is shown in Table 1. The interviewee listened/watched/used the trigger (oral document, video, smartphone app). Next, the interviews took place, and then the researchers transcribed the answers from audio format to electronic text for analysis purposes.

Table 1: Sample characteristics

\begin{tabular}{|l|l|l|}
\hline \multicolumn{1}{|c|}{ Case Study } & \multicolumn{1}{c|}{ Age Range } & \multicolumn{1}{c|}{ Gender } \\
\hline $\begin{array}{l}\text { Oral } \\
\text { documentation }\end{array}$ & 50 to 60 & 4 females \\
\hline Video & 50 to 70 & All males \\
\hline Smartphone app & 50 to 65 & All females \\
\hline
\end{tabular}

\section{Data Analysis and Results}

The researchers selected coding as the analysis approach. First, the researchers came up with coding and categories based on the literature review and the interviews' analysis as depicted in Appendix B (see Appendix B). Then, after generating all the categories, the researchers created themes to integrate many categories as shown in Figure 1. A top-down approach was used, since parts of the categories were developed from the literature review.

According to Myers (2013), the coding approach is a simple way to analyze data. It starts by identifying the analyzed text [12]. The following are the five steps that were used for analyzing the data:

- Sampling: in this step, the text was identified from literature as well as from interviews' transcript.

- Identified themes from both literature and interviews' transcript.

- Built codebook as shown in Appendix B.

- Marked texts, which focused on assigning codes to the text, as shown in Table 2.

- Constructed model, as shown in Figure 3, 4, and 5 , which shows the relationship among the themes and codes.

Table 2: Categories generated from interviews

\begin{tabular}{|c|c|}
\hline Code/Category & Quote Example \\
\hline Technical Skills & $\begin{array}{l}\text { "I think I have good } \\
\text { technical skills ......I } \\
\text { Really like the idea of the } \\
\text { app... Really easy to } \\
\text { follow and understand..." }\end{array}$ \\
\hline $\begin{array}{l}\text { Visiting primary } \\
\text { physician regularly }\end{array}$ & $\begin{array}{l}\text { "Yes, I go to my doctor } \\
\text { every three months... I }\end{array}$ \\
\hline
\end{tabular}

\footnotetext{
${ }^{1}$ This research has been classified as an exempt research by the IRB
}

\begin{tabular}{|c|c|}
\hline & $\begin{array}{l}\text { will talk with my doctor } \\
\text { about the disease and get } \\
\text { more information..." }\end{array}$ \\
\hline AD Checking & $\begin{array}{l}\text { "It is kind of scary. The } \\
\text { app shows so many } \\
\text { symptoms that are } \\
\text { scary.... Makes you } \\
\text { worry about it and check } \\
\text { for it." }\end{array}$ \\
\hline $\begin{array}{l}\text { More information about } \\
\text { the disease }\end{array}$ & $\begin{array}{l}\text { "I will get more } \\
\text { information from my } \\
\text { doctor; he is my } \\
\text { resource." }\end{array}$ \\
\hline $\begin{array}{l}\text { Informing } \\
\text { friends/family/others }\end{array}$ & $\begin{array}{l}\text { "... yes, I will discuss } \\
\text { that with my friends and } \\
\text { family, since discovering } \\
\text { the disease in its early } \\
\text { stage is very helpful." }\end{array}$ \\
\hline $\begin{array}{l}\text { Encouraging } \\
\text { friends/family/others }\end{array}$ & $\begin{array}{l}\text { "I will encourage my } \\
\text { family and friends to visit, } \\
\text { read, and search about } \\
\text { the disease..." }\end{array}$ \\
\hline Usefulness of the trigger & $\begin{array}{l}\text { "Really easy to follow } \\
\text { and understand...I think } \\
\text { it is helpful...I will use it" }\end{array}$ \\
\hline $\begin{array}{l}\text { Easy to access to the } \\
\text { trigger }\end{array}$ & $\begin{array}{l}\text { "It is a great little tool } \\
\text { for people to follow who } \\
\text { have AD, especially given } \\
\text { that it is free." }\end{array}$ \\
\hline $\begin{array}{l}\text { Encourage } \\
\text { friends/family/others to } \\
\text { use the app (For app only) }\end{array}$ & $\begin{array}{l}\text { "Really like the idea of } \\
\text { the app. If patient is } \\
\text { facing AD, he or she } \\
\text { should use this app." }\end{array}$ \\
\hline $\begin{array}{l}\text { Best and worst features } \\
\text { (For app only) }\end{array}$ & $\begin{array}{l}\text { "Best feature of this app: } \\
\text { Facts and figures were } \\
\text { the best and most } \\
\text { informative. Worst } \\
\text { feature of this app: Not } \\
\text { having enough good } \\
\text { exposure or technical } \\
\text { aptitude and enough } \\
\text { usage of technology." }\end{array}$ \\
\hline $\begin{array}{l}\text { Trigger recommendation } \\
\text { for improvement }\end{array}$ & $\begin{array}{l}\text { "It should be more } \\
\text { divided. More areas to } \\
\text { understand it clearer. } \\
\text { Separate phase for doctor } \\
\text { and separate phase or } \\
\text { area for patient." }\end{array}$ \\
\hline
\end{tabular}

Discovering a relationship between themes was important to answer the research question. In this stage, the researchers analyzed each case study separately since each one used a different trigger. To achieve the research goal and answer the question, there had to be a relationship between one or more themes and the Trigger Acceptance one. 


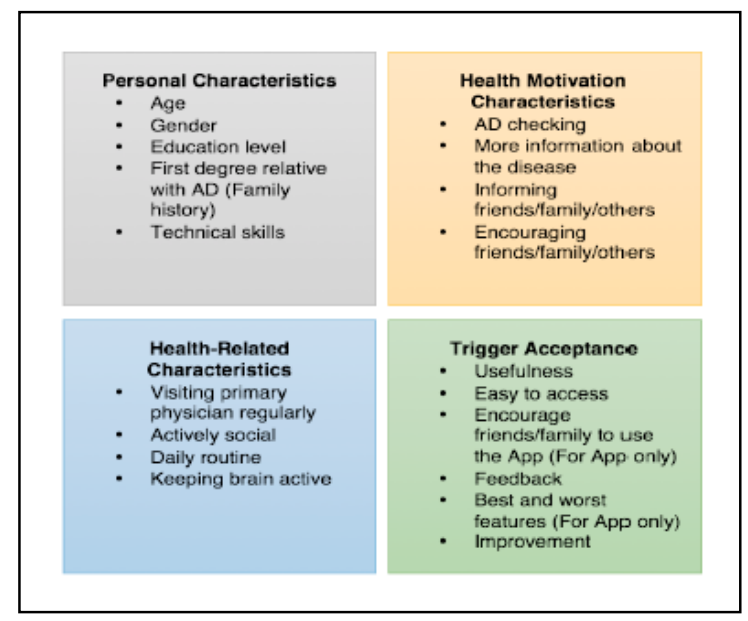

Figure 1: $A D$ themes

\subsection{Oral Documentation Case Study}

Going back and forth between the themes and transcript, the first author found several relationships between the themes and codes, as is shown in Figure 2. The following are some quotes from the interview transcript that was used in discovering the relationship between the themes:

One of the participants, who has a master's degree, stated that he does not visit a primary physician at all whereas others with high school degrees said they do.

"In the past I was visiting my primary physician yearly, but it was all ok. I wasn't having any problems, so I stopped doing that now. I just keep myself healthy, doing exercises... so I do take care of myself".

"I am not interested in that because I am always busy and works until night, so I did not have time for that."

People who reported visiting a primary physician regularly said they are more likely to search for more information about $\mathrm{AD}$, inform others about the disease, and encourage others to check for AD.

"Yes, I will search more about it, and I will defiantly be going to discuss that with my friends, so that they will be aware of it."

"Even though my sister is a medical assistance and my daughter is also in the medical field, which I think they all know about it, but I am going to tell them about it, so that they can ask their physician to check for it."

The relationship between the primary physician and the patient may affect the patient's decision of visiting her/his primary physician to check for $\mathrm{AD}$.

"I think I am going to change my primary physician not because she is not good, no she is nice... but I don't feel that I like her way in treatment... so that's why I don't think I will ask her about AD because I am not sure if I am going to get benefit about that."

A relationship was found between Personal Characteristics and Health-Motivation themes through the influence of the Trigger Acceptance theme ${ }^{2}$.

"You know I was not thinking about it before, but now after listening to you, I will definitely ask my doctor about it in my next visit.... My grandma has this disease ... now I remember my mom used to forgot a lot too, but she died at 59 with a heart attack, so I am not sure if she was having Alzheimer or not because she passed away so early... that means I do have family history of AD, I really did not think about that before."

"The explanations were good, and I really like the way you used examples to clarify the symptoms. You encourage me to keep my brain active, and to be more active socially to keep my brain in a good health."

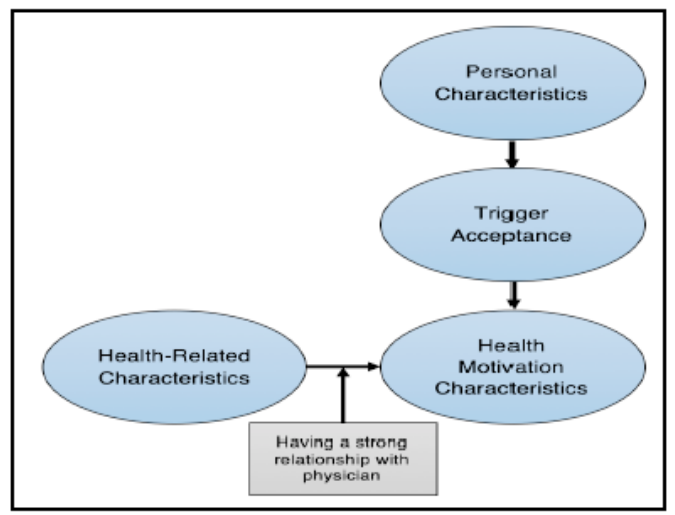

Figure 2: Oral documentation result

Based on FBM, the trigger is considered as a signal, since results showed that there is high ability

\footnotetext{
2 To get the tabular summary of the interviews, contact the first author atsarah.alismail@cgu.edu
} 
and high motivation. The analysis result shown in Figure 2, indicates that the Trigger Acceptance theme has a relationship with health motivation as well as Health-Related Characteristics, which confirms the research hypothesis.

\subsection{Video Case Study}

Based on analyzing the transcript and looking to the themes, the two main categories that have a relationship are the Health-Related Characteristics and Health-Motivation Characteristics themes as shown in Figure 3. The following are some quotes from the interview transcript that assisted the researchers in coming up with the relationships.

People who reported visiting their primary physician regularly and having a strong relationship with their doctors said that they are more likely to ask for $\mathrm{AD}$ checking, want to know more about the disease, inform others regarding the disease, and encourage others to check for the possibility of having the disease or not.

"Yes I visit my doctor every 3 months... I will ask my doctor to do the needed tests. Usually he is doing the necessary tests that I need... I will get more

information from my doctor, he is my resource... Yes, I will encourage my friends and family to visit, read, and search about the disease."

"Yes, I go to my doctor every 3 months... I will discuss with my doctor about the disease and get more information... yes, I will discuss that with my friends and family since discovering the disease in early stage is very helpful."

Even though some participants admitted having had some first-degree relative family members who were diagnosed and died with $\mathrm{AD}$, they did not want to check if they had the disease or not. However, according to Wikler et al. (2013), most of the people who used to be caregivers for $\mathrm{AD}$ patients were worried about having the disease in the future since there were first-relative blood relationship, which showed the opposite of this case study analysis result [13].

"Yes, my mother had the disease and she died because of the disease. It is very sad disease, and it is very costly. The government has to find a solution with the health insurance companies to limit the disease. I think one way to limit the disease is to educate the people more about disease... I do not think I need to check. I do not like to visit the primary doctor and I do not think I need to. I believe that what happened to me is on God hand."

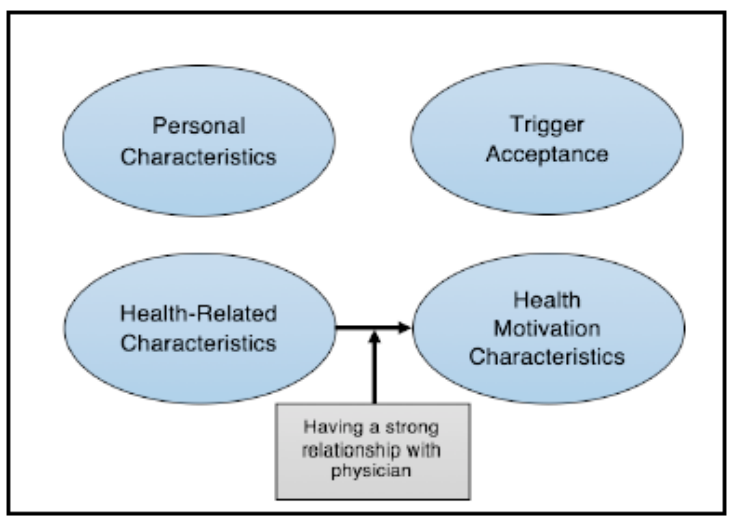

Figure 3: Video result

The trigger is considered to be a spark since there is high ability and low motivation. The analysis result showed that the used trigger failed to motivate the participants, which rejects the research's hypothesis. There is no relationship between the Trigger Acceptance theme and the other themes.

\subsection{Smart-Phone App Case Study}

The analysis showed that the Trigger Acceptance theme is related individually to all themes: Personal Characteristics, Health-Related Characteristics, and Health-Motivation Characteristics. Figure 4 shows the relationship between all themes. There is a relationship between the Personal Characteristics and Trigger Acceptance themes. As an illustration, people with high technical aptitude were really willing to use the app, while people with low technical skills were not very comfortable in using it.

"I think I have good technical skills ......I really like the idea of the app... Really easy to follow and understand... If patient is facing $A D$, he or she should use this app. It is a great little tool for people to follow who have AD."

"I am not an app person... using the phone is very frustrating...."

The Trigger Acceptance has a relationship with both the Health-Motivation theme and the Health-Related one. People who used the app said they are more willing to visit their physician and check for AD. After using the app and learning about AD, they expressed the desire to keep their brain active and healthy.

"Good discussions about things that I am interested 
that helps my brain work. I do things like crosser puzzles. I am very much active and deal a lot with keeping aging away."

Using the app was found to be highly motivating for people and encouraged them to visit their physician to check for $\mathrm{AD}$ and to encourage others to do so as well. Therefore, there is a relationship between the Trigger Acceptance theme and Health-Related one.

"I had not thought about it. I will take the tests as provided in the app and see the results and then visit the physician to ask about this."

"It is kind of scary. The app shows so many symptoms that are scary.... Makes you worry about it and check for it."

"I think app is a great idea. I would hope so it persuades people to check for AD. It persuades me."

"Yes. As I mentioned I want my friend to have a look at this as she has a parent who is struggling right now in the early stages and I think I want to share it with her right now."

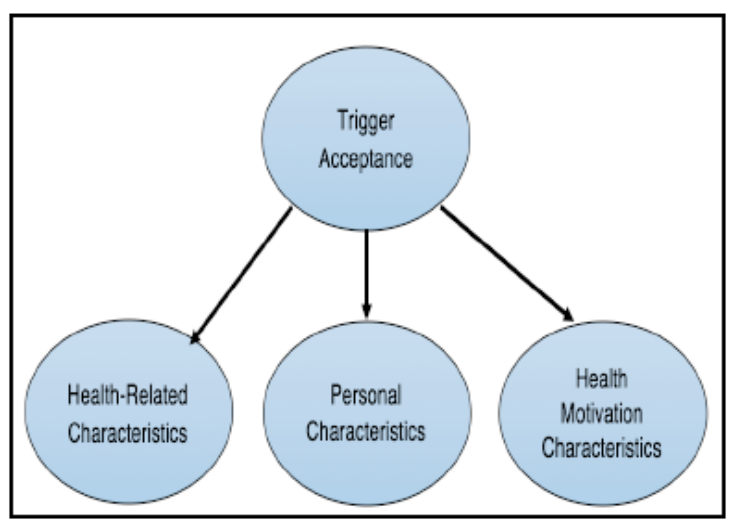

Figure 4: Smart-phone app result

Based on FBM, even though the interviewer demonstrated the app to the participants and gave them a chance to use it, the ability element was low since the app was not easy to use for participants with low technical skills. The trigger is considered as a facilitator since there was high motivation and low ability. Figure 4 shows that the Trigger Acceptance theme has a relationship with all the themes, which confirms the research hypothesis. Therefore, the participants who used the app are more willing to visit their primary physician to get checked for the disease.

\section{Discussions and Conclusion}

From the discussion above and with respect to the research objective, it can be said that oral documentation and the smartphone app triggers succeeded in motivating people to have the intention to change their behavior and to visit a/their primary physician regularly for early diagnosis of AD. On the other hand, the video trigger was unsuccessful in motivating people to have a desirable behavioral intention that would lead to behavior change. The smartphone app trigger is considered as a facilitator. The Trigger Acceptance theme in this case has a relationship with all other three themes, which are Personal, Health-Related, and Health-Motivation Characteristics. Thus, it confirms our first research hypothesis. The oral documentation trigger is considered to be a signal. The Trigger Acceptance theme in this case has a relationship with HealthRelated and Health-Motivation Characteristics themes. Thus, it confirms the second research hypothesis. The video trigger is considered to be a spark. Unlike the other two triggers, this trigger failed to motivate people to have the intention to change their behavior, and thus our first research hypothesis is rejected here. Moreover, based on our analysis, there is no relationship between the interviewee demographics and the themes.

Our results showed that the participants had the intention to change behavior. According to Triandis (1980), intentions are self-instructions to execute specific behaviors or to accomplish certain results [14]. Intention captures the motivational aspect, which influences the behavior [15]. However, there are several experimental studies about whether changing intentions causes behavior change [16]. Michie \& Abraham (2004) indicated that, if an intervention has successfully modified a behavior, this does not mean that behavior change occurs as a result of intention change [17].

One of the research limitations that may be considered as a starting point for future work is time constraints. This study is limited to behavioral intention due to time constraints. Therefore, for future research, the researchers will track the behavior change to prove that the participants take the action and ask for an early diagnosis of AD either via using the smartphone app or visiting a/ their primary physicians. Additionally, as a future work, we are going to expand the study through comparing other persuasive methods.

This research used a positivist and a top-down analysis approach. The use of FBM helped us understand our research objective more clearly. Two of the case studies were successful in motivating 
people to have the intention for a behavior change and help the participants acknowledge if they are prone to $\mathrm{AD}$ at an early stage. In the future, the researchers will incorporate more participants in order to increase generalizability of the research.

\section{References}

[1] Alzheimer's Association. "What Is Alzheimer's?" Alzheimer's Association, 2016. [Online]. Available: http://www.alz.org/alzheimers disease what is alzh eimers.asp. [Accessed: Feb. 2, 2016].

[2] Alzheimer's Association. "2014 Alzheimer's disease facts and figures," Alzheimer's \& Dementia, vol. 10 no. 2, pp. e47-e92, 2014.

[3] N. Almagloth. Interview from September 15, 2015.

[4] B.J. Fogg. "A behavior model for persuasive design," Proceedings of the 4th international Conference on Persuasive Technology, pp. 40, April 2009.

[5] National Institute on Aging. "About Alzheimer's Disease: Causes," US Department of Health and Human Services, 2015. [Online]. Available: https://www.nia.nih.gov/alzheimers/topics/causes.

[Accessed: March 2, 2016]

[6] M. Macgill. "Alzheimer's Disease: Causes, Symptoms and Treatment," Medical News Today, April 2016. [Online]. Available: http://www.medicalnewstoday.com/articles/159442.php. [Accessed: Feb.22, 2016].

[7] T.D. Bird. "Genetic Aspects of Alzheimer Disease," Genetics in Medicine: Official Journal of the American College of Medical Genetics, vol. 10 no. 4, pp. 231-239, Apr. 2008.

[8] J.L. Jankowsky, T. Melnikova, D.J. Fadale, G.M. Xu, H.H. Slunt, V. Gonzales, et al. "Environmental enrichment mitigates cognitive deficits in a mouse model of Alzheimer's disease," The Journal of Neuroscience, vol. 25 no. 21, pp. 5217-5224, May 2005.

[9] C. Merchant, M.X. Tang, S. Albert, J. Manly, Y. Stern, R. Mayeux. "The influence of smoking on the risk of Alzheimer's disease," Neurology, vol. 52 no. 7, pp. 140812,1999 .

[10] S.S. Ferebee. "Successful persuasive technology for behavior reduction: mapping to Fogg's gray behavior grid," Persuasive Technology. Berlin: Springer, 2010, pp. 70-81.

[11] Volleybrad. (2015, July 5). My father's behavior in the moderate stages of Alzheimer's disease. [YouTube video]. Available:

https://www.youtube.com/watch?v=VdzKXhyv tg.
[Accessed: Feb.10, 2016].

[12] M.D. Myers. Qualitative research in business and management, 2nd ed.London: SAGE Publications, 2013.

[13] E.M. Wikler, R.J. Blendon, \& J.M. Benson. "Would you want to know? Public attitudes on early diagnostic testing for Alzheimer's disease," Alzheimer's Research \& Therapy, vol. 5 no. 5, p.p. 1-11, 2013. [Online]. Available: doi:10.1186/alzrt206.

[14] H.C. Triandis. "Values, attitudes, and interpersonal behavior," in Nebraska Symposium of Motivation, vol. 27, H. E. Howe, Jr. \& M. Page, Eds. Lincoln, NB: University of Nebraska Press, 1980, pp. 195-259.

[15] I. Ajzen. "The theory of planned behavior," Organizational Behavior and Human Decision Processes, vol. 50 , pp. $179-211,1991$.

[16] A.J. Michie, \& C. Abraham. "Interventions to change health behaviours: Evidence-based or evidence-inspired?" Psychology and Health, vol. 19, pp. 29-49, 2004.

[17] T.L. Webb, \& P. Sheeran. "Does changing behavioral intentions engender behavior change? A meta-analysis of the experimental evidence," Psychological bulletin, vol. 132 no. 2, p. 249, 2006.H. E. Howe, Jr. \& M. Page, Eds. Lincoln, NB: University of Nebraska Press, 1980, pp. 195259. 


\section{Appendix A: Smartphone App with Interaction Features (Alzheimer's Association)}

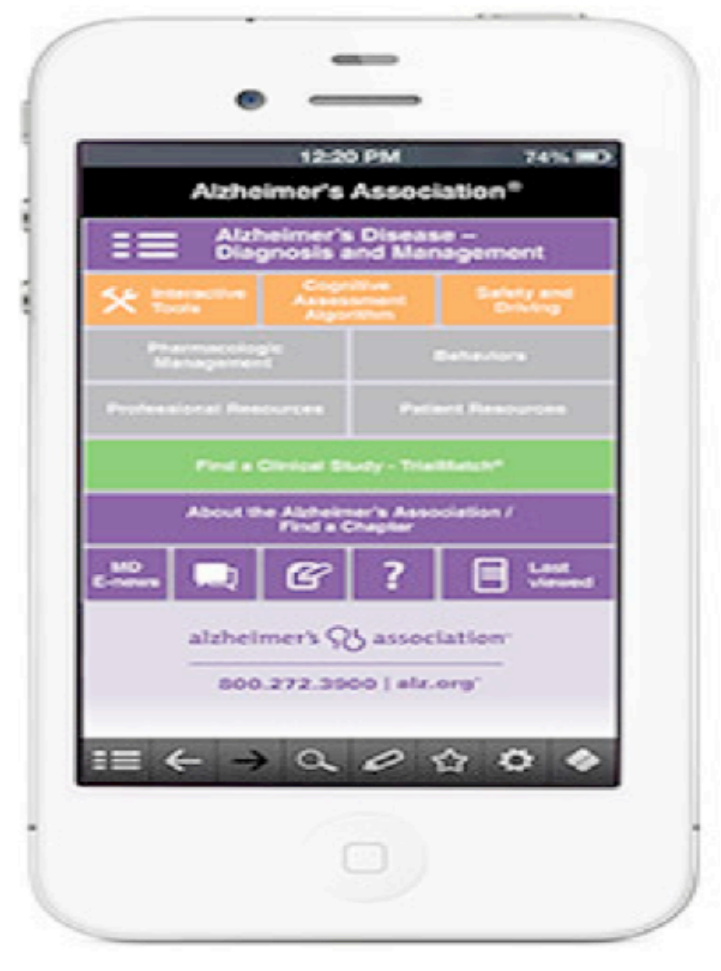

This App is a user-friendly technology that help users to understand, diagnose, prevent and curing Alzheimer's disease. It contains many interaction, screening processes and assessment tools that provide all useful information regarding Alzheimer's disease. It displays links so users can ask questions about the disease and also share documents directly with friends, caregivers and patients by email. It is very easy to download and use. Also, it gives the best possible information regarding AD.

Note: Researchers explained the App in details to the participants to simplify the ability to use. 
Appendix B: AD Categories/ Codes

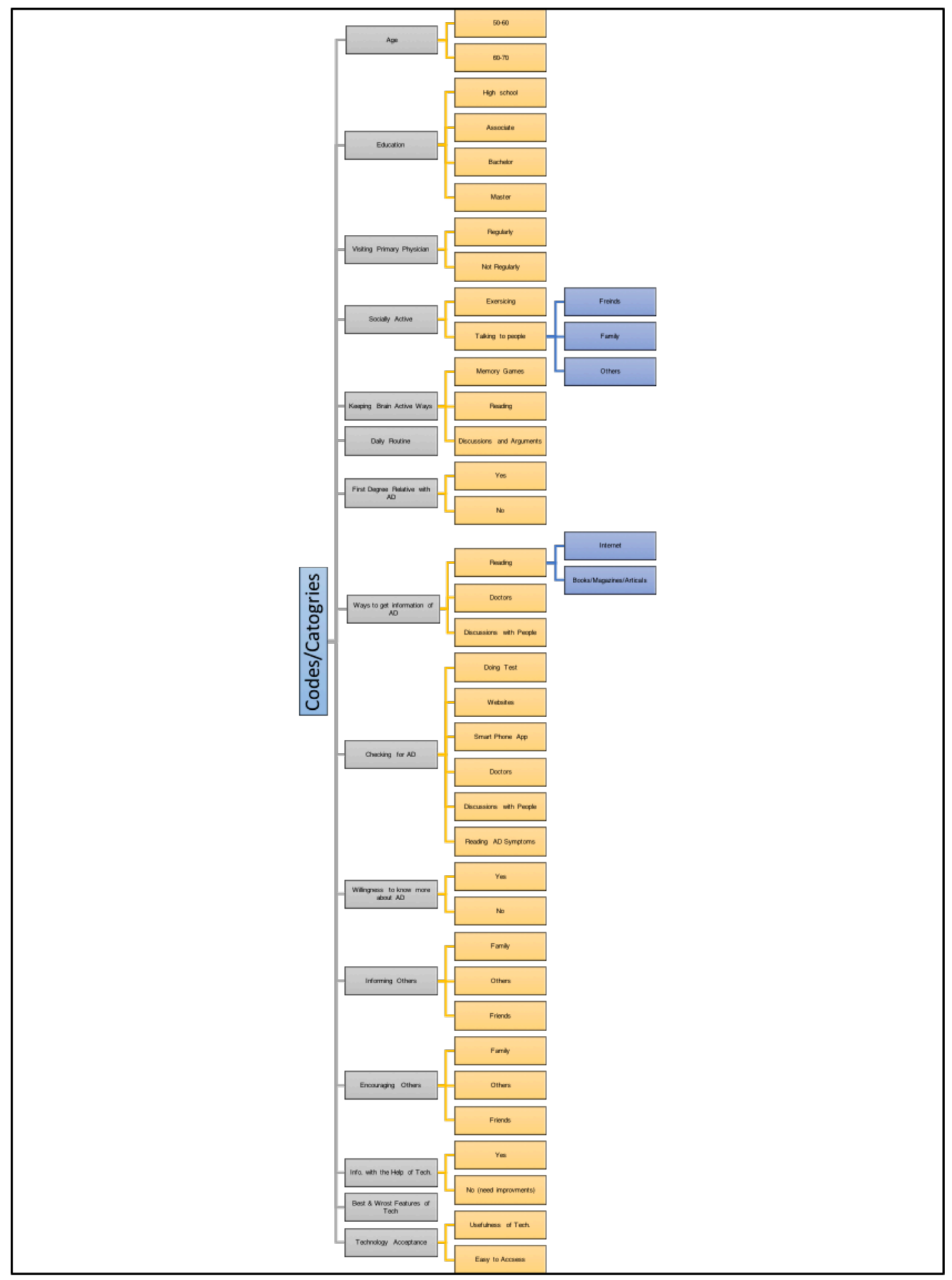

